\title{
Penentuan Pelarut untuk Adsorpsi Oryzanol dari Minyak Bekatul dengan Investigasi Kromatografi Lapis Tipis (Thin Layer Chromatography)
}

\author{
Ari Diana Susanti ${ }^{1,2, a,}$, Wahyudi Budi Sediawan ${ }^{2}$, Sang Kompiang Wirawan ${ }^{2}$, and \\ Budhijanto $^{2}$ \\ 1 Program Studi Teknik Kimia, Fakultas Teknik, Universitas Sebelas Maret, Jl. Ir. Sutami No. 36 A, \\ Surakarta, Indonesia \\ 2 Departmen Teknik Kimia, Fakultas Teknik, Universitas Gadjah Mada, Jl. Grafika No. 2, Yogyakarta, \\ Indonesia \\ E-mail: aaridiana@staff.uns.ac.id (Corresponding author)
}

\begin{abstract}
Oryzanol yang terkandung dalam minyak bekatul mempunyai kekuatan antioksidan lebih tinggi daripada vitamin $\mathrm{E}$ dan terbukti mempunyai efek hipokolesteromik sehingga berguna untuk kesehatan jantung dan pembuluh darah. Metode adsorpsi menggunakan adsorben silika merupakan salah satu metode isolasi oryzanol yang menjanjikan. Keberhasilan proses pemungutan oryzanol sangat ditentukan oleh pemilihan pelarut yang digunakan karena oryzanol merupakan senyawa ester sehingga sifatnya mirip dengan sifat trigliserida minyak bekatul yang ingin dipisahkan darinya. Oleh karena itu perlu ditentukan pemodifikasi pelarut sehingga diperoleh campuran pelarut yang cocok untuk proses tersebut. Modifikasi dilakukan terhadap pelarut utama n-heksana dan pemodifikasi potensial yang digunakan adalah etil asetat, diklorometana, kloroform, dan aseton. Performa campuran pelarut diuji menggunakan metode kromatografi lapis tipis (thin layer chromatography - TLC) menggunakan plat TLC silika gel grade 60. Hasil penelitian menunjukkan kombinasi $\mathrm{n}$-heksana/aseton $=85 / 15$ memberikan hasil pemisahan oryzanol terbaik, sedangkan kombinasi n-heksana/etil asetat $=90 / 10$ patut dipertimbangkan apabila elusi secara gradien dipilih dalam proses pemisahan.
\end{abstract}

Keywords: adsorpsi, kromatografi lapis tipis, minyak bekatul, oryzanol, silika gel.

EQUILIBRIUM Volume 16 No.2 Juli 2017

Online at http:/ / equilibrium.ft.uns.ac.id 


\section{Pendahuluan}

Minyak bekatul (Rice Bran Oil, RBO) mengandung oryzanol 0,9 - 2,9\% (Diack dan Saska, 1994) yang merupakan fitokimia antioksidan bernilai tinggi dalam bidang nutrisi (anti kanker dan anti kolesterol dalam functional food), farmasi (produksi obat penenang), dan kosmetik (krim dan lipstik) (Danielski dkk., 2005; Da Silva dkk., 2005). Penelitian menunjukkan efek hypocholesteromic RBO (Seetharamaiah dan Chandrasekhara, 1989; Xu dan Godber, 2001) dan kekuatan antioksidan oryzanol yang hampir empat kali lipat dari senyawa vitamin E (tokoferol dan tokotrienol) (Hiramitsu dan Armstrong, 1991). Pemakaiannya juga tidak memberikan efek alergi (Crevel et al., 2000) dan tidak dikelompokkan sebagai steroid, sehingga dapat dikonsumsi sebagai tambahan hormon (Xu dan Godber, 2001).

Indonesia dengan produksi padi terbesar ketiga di dunia sebanyak 70 juta ton/tahun (FAO, 20015) memiliki potensi sumber oryzanol yang cukup melimpah berupa bekatul (sekitar $10 \%$ berat gabah kering giling) yang pemanfaatannya saat ini masih terbatas untuk pakan ternak. Berbeda halnya dengan Jepang, China, Korea, dan Thailand yang telah melakukan pemanfaatan bekatul sebagai sumber minyak pangan dan sumber oryzanol.

Komponen penyusun minyak bekatul sebagian besar adalah trigliserida, sedangkan oryzanol merupakan senyawa fenolik campuran ester asam ferulat dengan komponen utama cycloartenol, $\beta$-sitosterol, 24 methylenecycloartenol, dan campesterol (Xu dan Godber, 1999). Struktur molekul komponen utama oryzanol dan komposisinya disajikan dalam Tabel 1.

Tabel 1. Struktur Molekul Komponen Utama Oryzanol dan Komposisinya

Struktur molekul

Metode adsorpsi banyak digunakan untuk mengkuantifikasi proses adsorpsi untuk pemisahan senyawa minor. Pemisahan lutein, pengujian magnesium silikat untuk mengadsorp FFA dari minyak sawit kasar, tahap pemucatan untuk industri pemurnian minyak nabati (Boki dkk., 1994), tahap penghilangan asam lemak bebas dan produk oksidasi lain (Toro-Vazquez dan Mendez-Montealvo, 1995). Adsorpsi juga digunakan untuk memperoleh komponen berharga semisal karoten dan vitamin $\mathrm{E}$ dari minyak (Baharin dkk., 1998; Chu dkk., 2004). Selain itu kuantifikasi proses adsorpsi untuk pengolahan limbah juga banyak dilakukan, semisal adsorpsi zat warna dan logam berat.

Percobaan menggunakan pemisah kontinyu CSEP ${ }^{\circledR}$ berbahan isian silika (paten oleh Advanced Separation Technologies) dengan prinsip simulated moving bed mampu meningkatkan konsentrasi oryzanol dalam minyak bekatul dari 1,2\% menjadi 12\% (Saska dan Rossiter, 1998) dan menunjukkan bahwa metode adsorpsi dapat digunakan untuk memungut oryzanol dari sistem minyak bekatul. Prosedur kromatografi berprinsip adsorpsi dinilai sangat efisien, tetapi scale-up untuk kapasitas komersial perlu diteliti lebih lanjut (Lai dkk., 2009). 
Eluen memegang peranan penting dalam keberhasilan pemisahan oryzanol dari minyak bekatul menggunakan adsorben silika. Berbagai kombinasi pelarut telah dipublikasi untuk memisahkan oryzanol untuk keperluan preparasi maupun analisis, diantaranya metanol/n-butanol/air, asetonitril/DCM/asam asetat, petroleum eter/etil asetat (Renuka dan Arumughan, 2007), n-heksana/etil asetat/asam asetat (Zigoneau, 2008), asetonitril/methanol (Imsanguan, 2008), isooktan/etil asetat/asam asetat/DMP (Hu, 1996), n-heksana/petroleum eter/dietil eter/methanol (Seetharamaniah dan Prabhakar, 1996), isooktan/etil asetat (Saska dan Rositter, 1998), n-heksana/asam asetat/ 2,2 dimetoksi propane (Diack dan Saska, 1994), dan n-heksana/etil asetat (Saska dan Rositter, 1998; Lai, 2005). Pilihan campuran pelarut yang digunakan oleh peneli sebelumnya itu belum mempertimbangkan toksisitas dan harga sehingga sulit diaplikasikan untuk komersialisasi proses.

Jenis dan komposisi pelarut juga menjadi pertimbangan penting dalam pengembangan metode adsorpsi skala komersial terkait keekonomiannya. Xu dkk. (2001) menyatakan ukuran molekul komponen penyusun oryzanol sangat berdekatan, sehingga tidak mempengaruhi kecepatan adsorpsi keseluruhan terhadap partikel adsorben. Pemilihan campuran pelarut didasarkan pada nilai polaritas dari pelarut. Kekuatan pelarut dapat dimodifikasi dengan cara penggunaan gabungan pelarut. Gabungan beberapa pelarut murni seringkali harus dipilih sebagai pelarut untuk mendapatkan efek pemisahan yang maksimal. Salah satu pertimbangan yang digunakan dalam pemilihan eluen adalah kekuatan pelarut yang dinyatakan sebagai polaritas pelarut, salah satunya dengan indeks Snyder (Miller, 2005).

Tabel 2 Polaritas Beberapa Pelarut berdasar Index Snyder

\begin{tabular}{clcc}
\hline No. & Pelarut & Rumus Molekul & Nilai Index Snyder \\
\hline 1. & n-Heksana & $\mathrm{C}_{6} \mathrm{H}_{14}$ & 0,1 \\
2. & Karbon Tetra Klorida & $\mathrm{CCl}_{4}$ & 1,6 \\
3. & Toluena & $\mathrm{C}_{6} \mathrm{H}_{5}-\mathrm{C}_{3}$ & 2,4 \\
4. & Benzena & $\mathrm{C}_{6} \mathrm{H}_{6}$ & 2,7 \\
5. & Di-Etil Eter & $\mathrm{C}_{2} \mathrm{H}_{5}-\mathrm{O}_{-}-\mathrm{C}_{2} \mathrm{H}_{5}$ & 2,8 \\
6. & Kloroform & $\mathrm{CHCl}_{3}$ & 4,1 \\
7. & Etanol & $\mathrm{CH}_{2} \mathrm{H}_{5}-\mathrm{OH}$ & 4,3 \\
8. & Etil Asetat & $\mathrm{CH}_{3}-\mathrm{COO}_{2} \mathrm{C}_{2} \mathrm{H}_{5}$ & 4,4 \\
9. & Aseton & $\mathrm{CH}_{3}-\mathrm{CO}-\mathrm{CH}_{3}$ & 5,1 \\
10. & Metanol & $\mathrm{CH}_{3}-\mathrm{OH}$ & 5,1 \\
11. & Asetonitril & $\mathrm{CH}_{3}-\mathrm{CN}$ & 5,8 \\
12. & Air & $\mathrm{H}_{2} \mathrm{O}$ & 10,2 \\
\hline
\end{tabular}

Penelitian ini ditujukan untuk menentukan campuran pelarut yang cocok untuk proses pemungutan oryzanol dari minyak bekatul.

\section{Metode Penelitian}

\section{Bahan}

Minyak bekatul komersial produksi Amorn Chai Ltd. Thailand. Oryzanol diperoleh dari Tokyo Chemical Industries Co., Ltd. dengan kemurnian lebih dari 99\% sesuai spesifikasi yang tercantum digunakan secara langsung tanpa pemurnian lanjut. Plat alumunium silika gel $60 \mathrm{~F}_{254}$, n-heksana, aseton, etil asetat, diklorometana (DCM), kloroform dan bahan kimia lain dengan tingkat kemurnian PA diperoleh dari Merck KGaA. Semua bahan diperoleh dari sumber komersial.

\section{Metode penelitian}

Sampel minyak bekatul dan oryzanol ditotolkan menggunakan micro haematocrit tube di titik yang berbeda pada batas bawah plat TLC yang telah diaktivasi. Plat TLC kemudian dimasukkan ke dalam chamber gelas yang berisi n-heksana dan telah jenuh dengan uap n-heksana. n-heksana akan bergerak sepanjang plat dan plat dikeluarkan dari chamber ketika n-heksana mencapai batas atas ujung plat. Pengamatan hasil elusi sampel dilakukan dengan menggunakan sinar lampu UV pada panjang gelombang $254 \mathrm{~nm}$ dan $330 \mathrm{~nm}$. Noktah yang muncul ditandai dengan pensil. Hasil elusi diamati lebih lanjut dengan mencelupkan plat TLC ke

Penentuan Pelarut untuk Adsorpsi Oryzanol dari Minyak Bekatul dengan Investigasi Kromatografi Lapis Tipis (Thin Layer Chromatography) (Ari Diana Susanti, Wahyudi Budi Sediawan, Sang Kompiang Wirawan, 
larutan $\mathrm{KMnO} 4$ (stain solution) dan dikeringkan untuk mempertegas noktah. Percobaan dilakukan ulang untuk n-heksana yang telah ditambah dengan etil asetat, DCM, kloroform atau aseton dalam berbagai perbandingan volume.

\section{Hasil dan Pembahasan}

Studi penentuan campuran pelarut dilakukan dalam dua tahap. Tahap pertama menentukan jenis pelarut kedua, sedang tahap kedua menentukan komposisi optimum n-heksana dan pelarut kedua. Tahap pertama dilakukan dengan uji kelarutan minyak bekatul dan oryzanol dalam campuran n-heksana : pelarut kedua = 90:10 dan dilanjutkan uji elusi menggunakan plat KLT. Pelarut kedua yang digunakan telah dipaparkan di Tabel 2. Hasil pengujian kelarutan menunjukkan etil asetat, di-kloro metana (DCM), kloroform, dan aseton berpotensi menjadi pelarut kedua. Uji elusi disajikan dalam Gambar 1 yang menunjukkan kemampuan berbagai campuran pelarut meng-elusi minyak bekatul dan oryzanol pada tingkat pemisahan yang berbedabeda.

Efek penambahan pelarut polar DCM dan kloroform kurang kuat untuk mengubah polaritas campuran pelarut terhadap oryzanol, sehingga oryzanol belum ter-elusi seperti yang ditunjukkan dalam Gambar 1(C) dan Gambar 1(D). Penggunaan etil asetat dan aseton sebagai pelarut kedua mampu mengelusi minyak bekatul dan oryzanol dan memberikan efek pemisahan terhadap oryzanol seperti yang ditunjukkan oleh Gambar 1(B) dan Gambar 1(E).

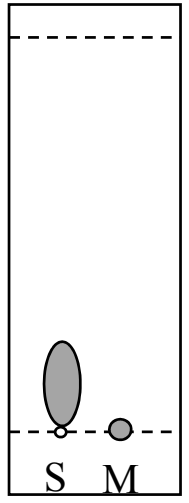

(A)

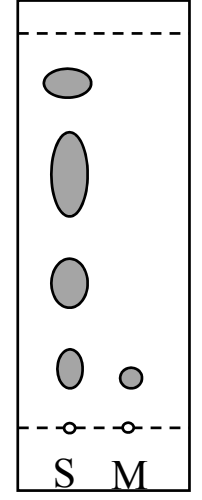

(B)

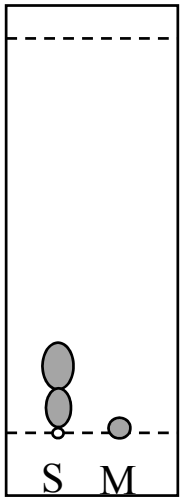

(C)

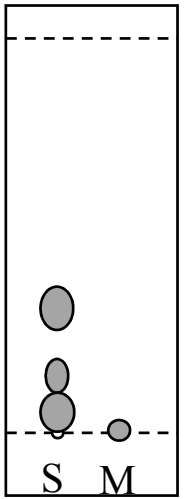

(D)

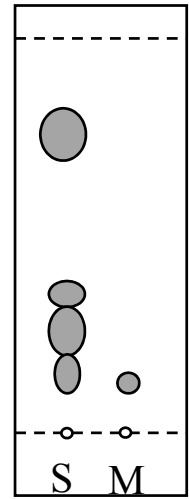

(E)

Gambar 1. Diagramatis Kromatogram Minyak Bekatul (S) dan Oryzanol (M) Menggunakan Pelarut (A) n-Heksana 100, (B) n-Heksana:Etil Asetat = 90:10, (C) n-Heksana:DCM = 90:10, (D) nHeksana:Kloroform $=90: 10$, dan (E) n-Heksana:Aseton $=90: / 10$

Interaksi molekul oryzanol dengan permukaan aktif silika gel menjadi sedikit lebih kuat dibanding interaksi minyak bekatul - silika gel maupun minyak bekatul - oryzanol. Molekul oryzanol akan sedikit tertahan di permukaan aktif silika gel dibanding minyak bekatul sehingga minyak bekatul akan terbawa aliran pelarut sedang oryzanol "tertinggal" dalam adsorben dan terjadi proses pemisahan. Oryzanol yang "tertinggal" di permukaan aktif silika gel dapat diperoleh kembali dengan proses desorpsi.

Berdasar hasil tahap pertama, dalam tahap kedua penentuan komposisi pelarut dilakukan untuk menentukan perbandingan volume etil asetat dan aseton terhadap n-heksana. Pengaruh penggunaan campuran pelarut n-heksana : etil asetat pada berbagai perbandingan volume disajikan dalam Gambar 2 dan pengaruh komposisi n-heksana : aseton disajikan dalam Gambar 3.

Penambahan etil asetat sebagai pelarut kedua terhadap proses adsorpsi mulai terlihat pengaruhnya pada perbandingan $\mathrm{n}$-heksana : etil asetat $=95: 5$. Gambar $2(\mathrm{~A})$ menunjukkan penambahan etil asetat sebanyak 5\% volume sudah menunjukkan efek pemisahan oryzanol tetapi jarak retensi sangat pendek, minyak bekatul tidak terpisah menjadi komponennya, dan minyak bekatul cenderung membentuk tailing. Jarak retensi, perbandingan jarak tempuh noktah sampel terhadap panjang plat, menunjukkan kemampuan pelarut meng-elusi molekul sampel untuk memberikan efek pemisahan dan kadang mengindikasikan kekuatan interaksi molekul terhadap permukaan silika gel dalam plat. Jarak retensi oryzanol yang kecil menunjukkan pelarut tidak cukup kuat meng-elusi oryzanol. Perolehan ekstrak oryzanol akan memerlukan 
waktu yang lama dan sebagian besar waktu proses adsorpsi - desorpsi akan merupakan proses pemungutan minyak bekatul, sehingga campuran n-heksana $:$ etil asetat $=95: 5$ tidak dapat digunakan sebagai pelarut.

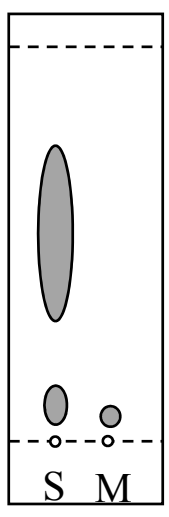

(A)

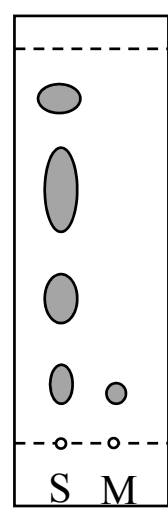

(B)

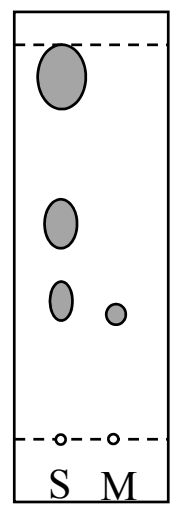

(C)

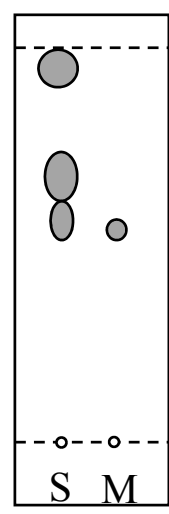

(D)

Gambar 2. Diagramatis Kromatogram Pemisahan Minyak Bekatul (S) dan Oryzanol (M) Menggunakan Campuran Pelarut dengan Perbandingan n-Heksana : Etil Asetat (A) 95:5, (B) 90:10, (C) 85:15, dan (D) 80:20.

Gambar 2 (B) dan Gambar 2 (C) menunjukkan penambahan etil asetat sebanyak 10\% dan 15\% volume, yang memberikan efek pemisahan oryzanol - minyak bekatul cukup baik. Jarak retensi oryzanol pada penggunaan etil asetat 15\% lebih tinggi dibanding jarak retensi penggunaan etil asetat 10\% sehingga ekstrak oryzanol lebih cepat diperoleh pada penggunaan etil asetat 15\%. Penambahan etil asetat sebanyak $20 \%$ volume ditampilkan dalam Gambar 2 (D) mengakibatkan interaksi oryzanol - silika gel kembali melemah sehingga efek pemisahan oryzanol dari minyak bekatul berkurang. Jarak retensi oryzanol dan minyak bekatul hampir mirip. Interaksi molekul oryzanol dan molekul minyak bekatul terhadap molekul pelarut cenderung meningkat sehingga oryzanol dan minyak bekatul lebih mudah terbawa aliran pelarut. Secara umum terlihat bahwa peningkatan fraksi etil asetat dalam campuran pelarut akan mempercepat perolehan oryzanol, tetapi minyak bekatul menjadi kurang terpisahkan.

Pengaruh penggunaan campuran pelarut $\mathrm{n}$-heksana : aseton pada berbagai perbandingan volume disajikan dalam Gambar 3. Penggunaan aseton pada konsentrasi 10\% volume ditunjukkan oleh Gambar 3 (A) memperlihatkan telah terjadi pemisahan oryzanol - minyak bekatul tetapi dengan jarak pemisahan sempit sehingga operasional proses adsorpsi - desorpsi tidak mudah.

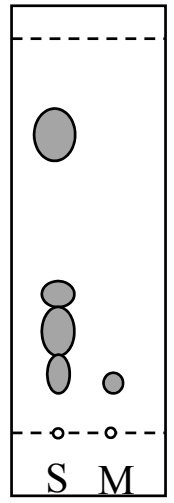

(A)

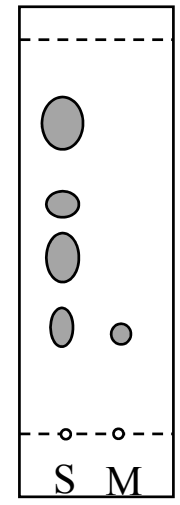

(B)

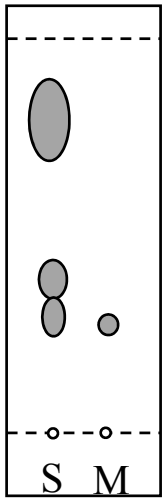

(C)

Gambar 3. Diagramatis Kromatogram Pemisahan Minyak Bekatul (S) dan Oryzanol (M) Menggunakan Campuran Pelarut dengan Perbandingan n-Heksana: Aseton $=(A)$ 90:10, (B) 85:15, dan (C) 80:20.

Penentuan Pelarut untuk Adsorpsi Oryzanol dari Minyak Bekatul dengan Investigasi Kromatografi Lapis Tipis (Thin Layer Chromatography) (Ari Diana Susanti, Wahyudi Budi Sediawan, Sang Kompiang Wirawan, 
Berdasar tahapan penentuan campuran pelarut di atas, diperoleh campuran pelarut yang potensial adalah nheksana $:$ etil asetat $=90: 10$ dan n-heksana $:$ aseton $=85: 15$. Pelarut aseton lebih polar dibanding pelarut etil asetat karena karbo - kation dari gugus keton lebih polar dibanding karbo - kation dari gugus ester. Penambahan aseton ke dalam pelarut n-heksana akan meningkatkan polaritas pelarut n-heksana. Kepolaran pelarut akan meningkatkan kepolaran permukaan silika gel sehingga oryzanol yang bersifat lebih polar akan relatif tertahan dalam adsorben akibat interaksi elektrosatis permukaaan polar silika gel - molekul polar oryzanol. Sedangkan molekul trigliserida yang non polar akan terbawa aliran pelarut tanpa mengalami hambatan elektrostatis permukaan silika gel. Perbedaan hambatan aliran ini akan membuat oryzanol terpisah secara relatif dari trigliserida minyak bekatul dan tertahan di adsorben silika gel untuk kemudian dapat diperoleh kembali dalam kemurnian tinggi pada tahap desorpsi.

\section{Kesimpulan}

Penambahan pelarut polar (etil asetat dan aseton) ke dalam pelarut non polar (n-heksana) dapat meningkatkan performa pemisahan oryzanol dari trigliserida komponen minyak bekatul menggunakan metode adsorpsi. Kombinasi n-heksana: aseton (85:15) memberikan hasil pemisahan yang optimal dan dapat digunakan sebagai pelarut dalam proses pemisahan menggunakan kromatografi kolom secara isokratik.

\section{Pustaka}

Baharin, B. S. et al., 1998, Separation of Palm Carotene from Crude Palm Oil by Adsorption Chromatography with a Synthetic Polymer Adsorbent, JAOCS, vol. 75

Boki, K. et al., 1994, Bleaching Rapeseed and Soybean Oils with Synthetic Adsorbents and Attapulgites, JAOCS, vol.71

Chu, B.S. et al., 2004, Separation of Vitamin E from Palm Fatty Acid Distillate using Silica: I Equilibrium of Batch Adsorption, Journal of Food Engineering, vol. 62

Crevel, R.W.R., Kerkhoff, M.A.T., and Konong, M.M.G., 2000, Allergenicity of Refined Vegetable Oils, Food Chem. Toxicology, 38, pp. 385-387

Da Silva, M.A., Sanches, C., Amante, E.R., 2006, Prevention of Hydrolytic Rancidity in Rice Bran, Journal of Food Engineering, 75, pp. 487-491

Danielski, L., Zetzl, C., Hense, H., and Brunner, G., 2005, A Process Line for The Production of Raffinated Rice Oil from Rice Bran, Journal of Supercritical Fluids, 34, pp. 133-141

Diack, M., and Saska, M., 1994, Separation of Vitamin E And $\gamma$-Oryzanols from Rice Bran by NormalPhase Chromatography, JAOCS, 71, pp.1211-1217

Hiramitsu, T., and Amstrong, D.,1991, Preventive Effect of Antioxidants on Lipid Peroxidation in the Retina, Ophthalmic Research, 23, pp. 196-203

Hu, W., Wells, J.H., Shin, T., and Godber, J.S., 1996, Comparison of Isopropanol and Hexane for Extraction of Vitamin E and Oryzanols from Stabilized Rice Bran, JAOCS, 73, pp. 1653-1656

Imsanguan, P., Roaysubtawee, A., Borirak, R., Pongamphai, S., Douglas, S., and Douglas, P. L., 2008, Extraction of $\alpha$-tocopherol and $\gamma$-oryzanol from Rice Bran, LWT, 41, pp. 1417-1424

Lai, P., Li, K.Y., Lu, S., and Chen, H.H., 2009, Analytical Method: Phytochemicals and Antioxidant Properties of Solvent Extracts from Japonica Rice Bran, Food Chemistry, 117, pp. 538-544

Miller, J.M., 2005, Chromatography: Concepts and Contrasts, John Wiley \& Sons, 104-107

Renuka Devi, R. and Arumughan, C., 2007, Phytochemical Characterization of Defatted Rice Bran and Optimization of a Process for Their Extraction and Enrichment, Bioresource Technology, 98, pp. 30373043

Saska, M., and Rositter, G.J., 1998, Recovery of $\gamma$-Oryzanol from Rice Bran Oil with Silica-Based Continuous Chromatography1, JAOCS, 75, pp. 1421-1427

Seetharamaiah, G.S. and Chandrasekhara, N., 1989, Studies on Hypocholesterolemic Activity of Rice Bran Oil, Atherosclerosis, 78, pp. 219-223

Seetharamaiah, G.S., and Prabhakar, J.V., 1986, Oryzanol Content of Indian Rice Bran Oil and Its Extraction from Soapstock, J. Food Sci. Technol., 23, pp. 270-273

Toro-Vazquez, J. F., dan Mendez-Montealvo, G., 1995, Competitive Adsorption among Sesame Oil Components in a Concentrated Miscella System, JAOCS, vol. 72 
Xu, Z. and Godber, J. S., 1999, Purification and Identification of Components of $\gamma$-oryzanol in Rice Bran Oil, J. Agric. Food Chem., 47, pp. 2724-2728

Xu, Z., Hua, N., and Godber, J.S., 2001, Antioxidant Activity of Tocopherols, Tocotrienols, and $\gamma$ Oryzanol Components from Rice Bran Against Cholesterol Oxidation Accelerated by 2,2-Azobis (2methylpropionamidine) Dihydrochloride, J. Agric. Food Chem., 49, pp. 2077- 2081

Zigoneanu, I.G., Williams, L., Xu, Z., and Sabliov, C.M., 2008, Determination of Antioxidant Components in Rice Bran Oil Extracted by Microwave-assisted Method, Bioresource Technology, 99, pp. 4910-4918

Penentuan Pelarut untuk Adsorpsi Oryzanol dari Minyak Bekatul dengan Investigasi Kromatografi Lapis Tipis (Thin Layer Chromatography) (Ari Diana Susanti, Wahyudi Budi Sediawan, Sang Kompiang Wirawan, 